\title{
Supravalvular aortic stenosis in a twin
}

\author{
GRAEME NEILSON AND KENNETH F. HOSSACK \\ From the Cardiac Investigation Unit, The Prince Charles Hospital, Chermside, Brisbane, Queensland, \\ Australia
}

SUMMARY A case of subvalvular aortic stenosis in one of a set of dissimilar twins is reported. The case is discussed in terms of the aetiological factors involved and supports the view that supravalvular aortic stenosis is not environmental and may be genetic in origin.

The triad of supravalvular aortic stenosis, 'characteristic facies', and mental retardation was described by Williams et al. in 1961. Subsequently Beuren et al. (1964) showed that the syndrome also included peripheral pulmonary artery stenosis, systemic artery stenosis, and dental abnormalities. It was suspected by others and documented by Garcia et al. (1964) that as neonates these children have hypercalcaemia. In 1965 Logan et al. described patients who had a familial form of supravalvular aortic stenosis with normal facies and normal mental development.

This report concerns a set of dissimilar twins, one of whom had the supravalvular aortic stenosis syndrome.

\section{Case report}

The children were delivered by caesarean section at 38 weeks' gestation. The pregnancy was normal. There was no history of maternal rubella and no family history of heart disease. The boy had been referred at the age of 6 years because of tiredness and the presence of a heart murmur. The child had not fed well as a neonate and milestones were slower than the normal twin.

On examination the boy had a pleasant disposition. He had the typical facies and associated dental abnormalities of supravalvular aortic stenosis syndrome. The left brachial artery pulsation was reduced in volume in comparison with the right. The femoral artery pulsation was not delayed. The jugular venous pressure was normal. There was a palpable left ventricle impulse and a loud ejection murmur associated with a thrill at the base radiating to the neck. The remainder of the physical examination was normal, in particular there were no renal bruits or peripheral artery bruits. Developmental level, using the Gesell developmental schedule, was 4 to 5 years.
The plain chest $x$-ray film showed normal lung fields and normal sized heart. Skull and abdominal $x$-rays and intravenous urogram were normal. Bone age was normal. Electrocardiogram was consistent with moderate left ventricular hypertrophy. Full blood count, serum electrolytes, serum calcium, blood urea, and serum creatinine were normal.

The following pressures were recorded at right and left heart catheterisation (Table).

Table

\begin{tabular}{ll}
\hline Site & $\begin{array}{l}\text { Pressure } \\
\mathrm{mmHg}\end{array}$ \\
\hline Pulmonary capillary venous pressure & mean 9 \\
Right pulmonary artery & $20 / 15$ \\
Main pulmonary artery & $33 / 15$ \\
Right ventricle & $33 / 5$ \\
Right atrium & mean 5 \\
Left ventricle & $210 / 10$ \\
Proximal ascending aorta & $210 / 95$ \\
Distal ascending aorta & $155 / 80$ \\
\hline
\end{tabular}

Cineangiograms were performed with injections in both left and right ventricles. These showed severe supravalvular aortic stenosis extending into the arch of the aorta. There was mild stenosis at the origin of the right pulmonary artery (Figs. 1 and 2).

Physical examination, chest $x$-ray film, and electrocardiogram were normal in the female twin.

\section{Discussion}

Studies of diseases occurring in twins have been used to differentiate genetic and environmental factors involved in the aetiology of such disease states. Initially there was considerable speculation as to the role of vitamin $\mathrm{D}$ in causing the supravalvular aortic stenosis syndrome. Coleman (1965) showed that large doses of vitamin $\mathrm{D}$ compounds 


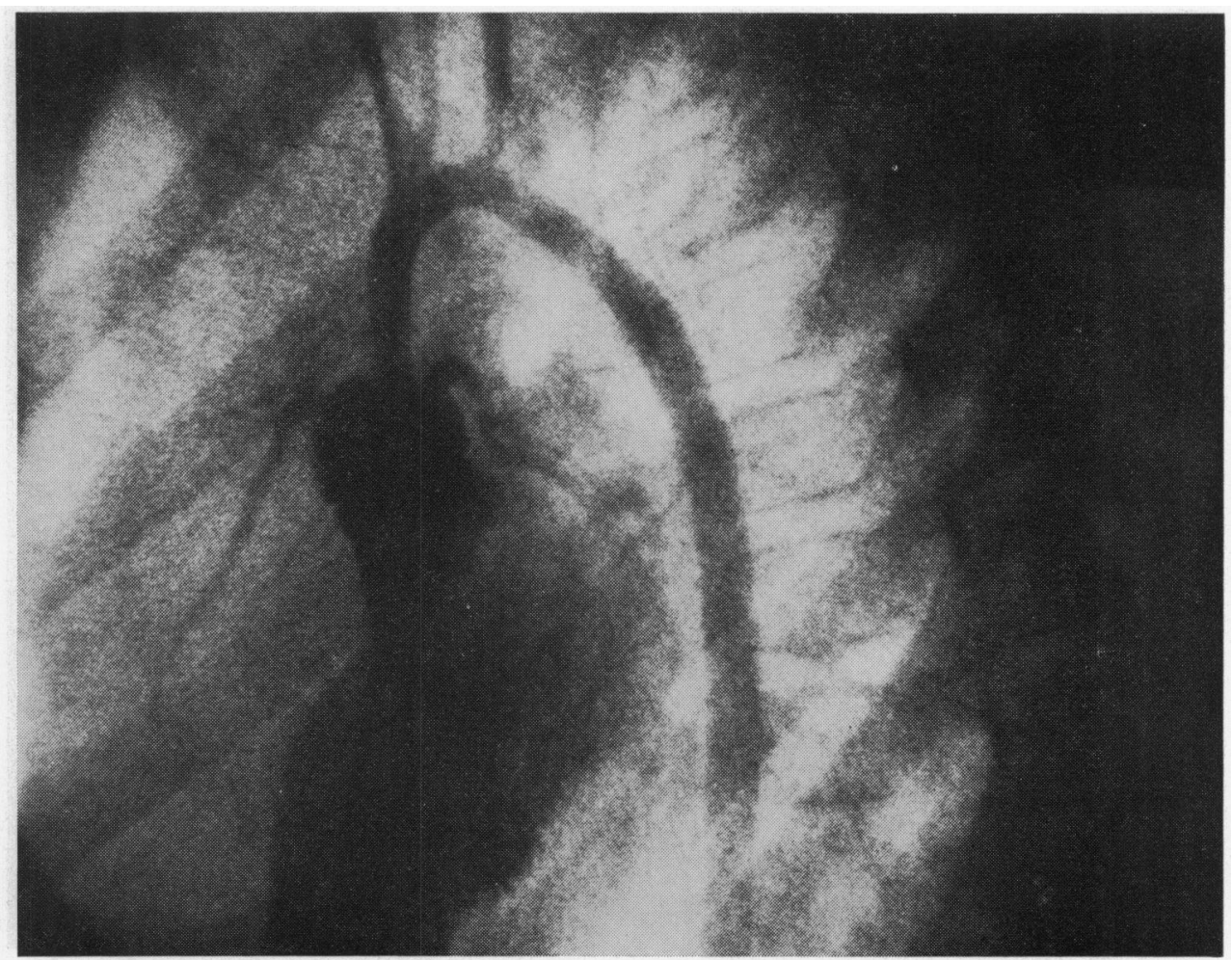

Fig. 1 An injection has been performed in the left ventricle in the lateral projection. The severe supravalvular stenosis is shown extending into the arch and descending aorta.

fed to pregnant rabbits consistently caused vascular lesions in their offspring. In 1966 Friedman and Roberts showed that vitamin D crossed the human placenta and they also reported vascular lesions occurring in offspring of rabbits exposed to high doses of vitamin $\mathrm{D}$. In general most would agree that vitamin $\mathrm{D}$ excess cannot be incriminated as a cause of supravalvular aortic stenosis in humans. Fraser et al. (1966) are critical of the vitamin D theory, and point out the spectrum of infantile hypercalcaemia. Some children present as neonates with hypercalcaemia, the cardiac lesions being absent or unrecognised. Others present later because of the cardiovascular abnormalities; as neonates they have a history of low birthweight, poor feeding, and failure to thrive. Black and Bonham Carter (1963) have reported 5 patients who had typical facies and murmurs of supravalvular aortic stenosis and history at birth suggestive of infantile hypercalcaemia.

Absence of history of maternal rubella and only one of the twins being affected make such viral aetiology for the supravalvular aortic stenosis highly improbable.
Chromosomal abnormalities have not been detected in patients with supravalvular aortic stenosis (Beuren et al., 1964).

Twin boys having typical facies with supravalvular aortic stenosis have been described (Page et al., 1969). Twin girls with infantile hypercalcaemia, peripheral pulmonary artery stenosis, and hypoplasia of the aorta have been described (Wiltse et al., 1966).

Underhill et al. (1971) from their studies of the familial form of supravalvular aortic stenosis suggested that the mode of inheritance appeared to be an autosomal dominant with incomplete penetrance in males.

Martin and Moseley (1973) reported their experience of supravalvular aortic stenosis and reviewed other published cases. In over half the cases of the 'familial' form no family history was present, so it seems that some of these cases were sporadic. There was also a large spectrum of combinations in the 'idiopathic hypercalcaemic' group. They suggested that both types might be the expression of a common metabolic defect genetically determined.

This report supports the hypothesis that the 


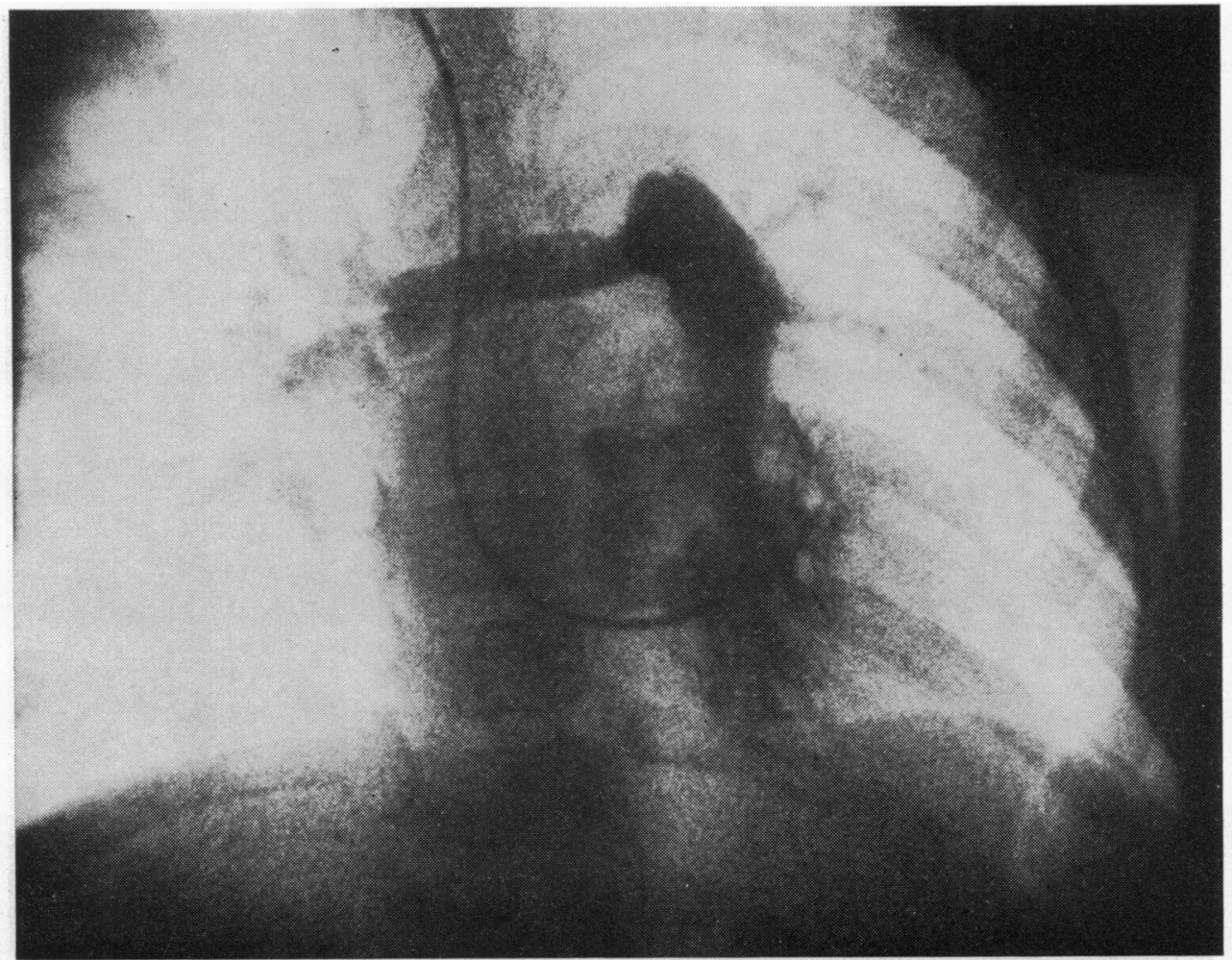

Fig. 2 An injection has been performed in the right ventricle in a shallow right anterior oblique projection. Stenosis at the origin of the right pulmonary artery is shown confirming the haemodynamic findings. There were no other lesions in the pulmonary arteries.

aetiology of supravalvular aortic stenosis is not environmental but is probably genetic in origin.

The length of involvement of the aorta in this patient is unusual.

\section{References}

Beuren, A. J., Schultze, C., Eberle, P., Harmjanz, D., and Apitz, J. (1964). The syndrome of supravalvular aortic stenosis, peripheral pulmonary stenosis, mental retardation and similar facial appearance. American fournal of Cardiology, 13, 471-483.

Black, J. A., and Bonham Carter, R. E. (1963). Association between aortic stenosis and facies of severe infantile hypercalcaemia. Lancet, 2, 745-749.

Coleman, E. N. (1965). Infantile hypercalcaemia and cardiovascular lesions. Evidence, hypothesis and speculation. Archives of Disease in Childhood, 40, 535-540.

Fraser, D., Langford Kidd, B. S., Kooh, S. W., and Paunier, L. (1966). A new look at infantile hypercalcemia. Pediatric Clinics of North America, 13, 503-525.

Friedman, W. F., and Roberts, W. C. (1966). Vitamin D and the supravalvular aortic stenosis syndrome. Circulation, 34, 77-86.

Garcia, R. E., Friedman, W. F., Kaback, M. M., and Rowe, R. D. (1964). Idiopathic hypercalcaemia and supravalvular aortic stenosis. Documentation of a new syndrome. New England fournal of Medicine, 271, 117-120.

Logan, W. F. W. E., Wyn Jones, E., Walker, E., Coulshed, N., and Epstein, E. J. (1965). Familial supravalvular aortic stenosis. British Heart fournal, 27, 547-559.

Martin, E. C., and Moseley, I. F. (1973). Supravalvular aortic stenosis. British Heart fournal, 35, 758-765.

Page, H. L., Jr., Vogel, J. H. K., Pryor, R., and Blount, G. S. (1969). Supravalvular aortic stenosis. Unusual observations in three patients. American fournal of Cardiology, 23, 270-277.

Underhill, W. L., Tredway, J. B., D’Angelo, G. J., and Baay, J. E. W. (1971). Familial supravalvular aortic stenosis. American fournal of Cardiology, 27, 560-565.

Williams, J. C. P., Barratt Boyes, B. G., and Lowe, J. B. (1961). Supravalvular aortic stenosis. Circulation, 24, 1311-1318.

Wiltse, H. E., Goldbloom, R. B., Antia, A. U., Ottesen, O. E., Rowe, R. D., and Cooke, R. E. (1966). Infantile hypercalcemia syndrome in twins. New England fournal of Medicine, 275, 1157-1160.

Requests for reprints to Dr Graeme Neilson, Cardiac Investigation Unit, The Prince Charles Hospital, Rode Road, Chermside, Brisbane 4032, Queensland, Australia. 